\title{
Epidemic Change-Current Traits on Stein-Leventhal Syndrome (SLS)
}

\author{
Nirav R Soni* \\ Department of Quality Assurance, Gujarat Technological University, India
}

Submission: November 07, 2017; Published: December 15, 2017

*Corresponding author: Nirav R Soni, Department of Quality Assurance, Gujarat Technological University, Ahmedabad, India, Email: nirav_sonic@yahoo.com

\begin{abstract}
Stein-Leventhal Syndrome (SLS) is the major health problem that affects about $12-21 \%$ of women of fertility age. It causes important distress to women and so many costs for healthcare accounting. In fact, SLS is mainly causes of female infertility. The symptom of SLS is the changing definitions and a range of symptoms have made the path to diagnosis for many women difficult up to $70 \%$ of women with SLS in the community remain undiagnosed. The National Institutes of Health (NIH) assumed that $50 \%$ of women with SLS will become diabetic or prediabetic by age 40 . There was a different available studies shown that the women with SLS to be at higher risk for suicide as well as endometrial cancer, ovarian cancer and breast cancer. SLS affects the quality of life and psychological disorders like worsen anxiety and depression either due to the features of SLS or due to the diagnosis of chronic symptoms.
\end{abstract}

Keywords: Sign and symptoms; Management and lifestyle; Complications

\section{Introduction}

SLS is the most common hormonal disorder among women between the ages of 18 and 44 . It is one of the leading causes of infertility. It is often associated with psychological impairments including depression and other mood disorders and metabolic derangements [1]. There are a number of definitions of SLS, the Rotterdam consensus is the most widely accepted across Europe, Asia and Australia was the definition used for the guideline. Polycystic means "many cysts," and SLS regularly causes clusters of small, pearl-sized cysts in the ovaries [2,3]. The cysts are fluidfilled and immature eggs. SLS is also known as "Poly Cystic Ovary Syndrome (PCOS)". Women with SLS produce a small amount of male hormones known as androgens, which give to some of the symptoms of the condition [2-4] (Figure 1).

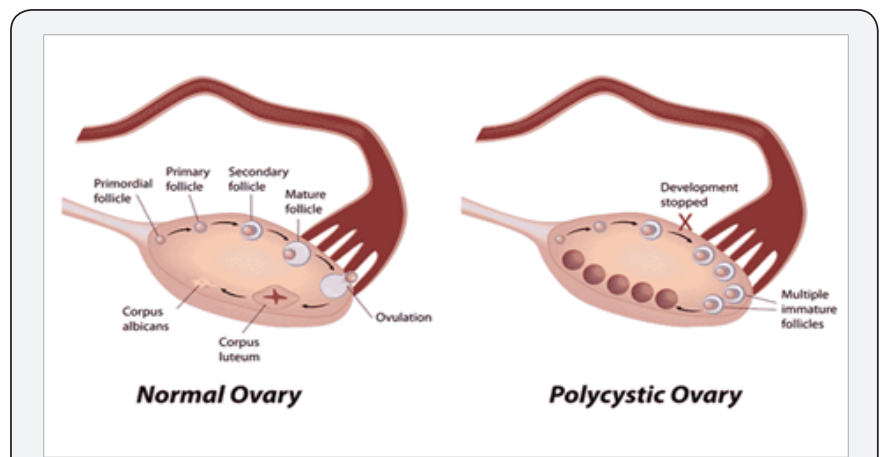

Figure 1: Development of SLS.

\section{Signs and symptoms of SLS}

It includes irregular or absent of menstrual cycle, it may be heavy periods, unwanted hair growth on a face, gain weight, acne or skin rashes, pelvic pain, pregnancy problem, patches of thick, darker, velvety skin. Associated with potential complications includes type-II diabetes, obesity, obstructive sleep apnea $[1,4,5]$ heart disease [3], behavior disorders and acanthosis nigricans, Hashimoto diseases, endometrial cancer and breast cancer [6]. Also, a large number of people diagnosed with rheumatoid arthritis (RA), multiple sclerosis and lupus combined [5]. Cysts may be detectable by ultrasound (US). Other conditions that produce similar symptoms involved adrenal hyperplasia, hyperprolactinemia and hypothyroidism [3-7]. 5-10\% of women of childbearing age are affected and with $<50 \%$ of women diagnosed. SLS is only responsible for $70 \%$ of infertility issues in women who have difficulty ovulating. Post-menopausal women can also suffer from SLS. Some studies have shown that approximately $40 \%$ of patients with diabetes between the ages of 20-50 have SLS. In addition, some studies have found that if a mother has SLS, there is a $50 \%$ chance that her daughter will have this syndrome. According to the "U.S. Department of Health and Human Services", between 1/10 and 1/20 women of childbearing age suffers from SLS. The condition currently affects up to 5 million women in the same country [5-8] (Figure 2). 


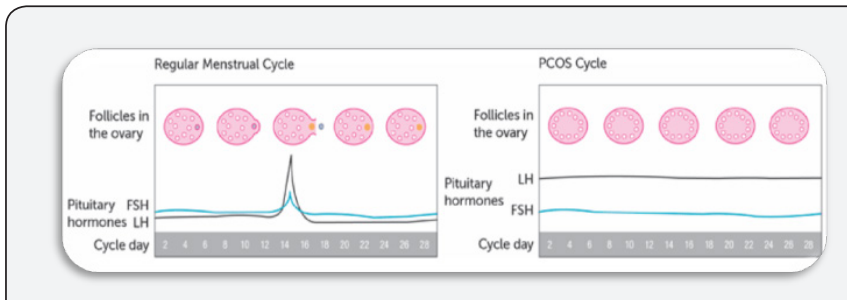

Figure 2: Normal V/S SLS menstrual Cycle.

\section{Current management option for SLS [9-15]}

The management of SLS can include: Lifestyle modifications: Increasing physical activity levels or yoga or gym and eating a healthy diet [6]. Weight reduction: Research has shown that even five to $10 \%$ weight loss can provide significant health benefits [7-9].

\section{Medical treatment [10-15]}

\section{The oral contraceptive pill}

Hormonal medication: To block hormones like testosterone (for example, spironolactone).

Infertility medications: Clomiphene citrate (sold as Clomid) or metformin may be taken orally to bring about ovulation. For infertility, "clomiphene" is first-line treatment. For metabolic disturbances and for improving menstrual regularities problem, Metformin is of limited or no benefit for managing abnormally facial hair growth is known as hirsutism, acne, or infertility. Overall, thiazolidinediones have not favourable risk-benefit ratio.

\section{Psychological counseling [11-13]}

Novel therapy [12-14]: Pineol \& inositol are recently in trials for the management option. The various reason for taking inositol based powder and other medications. Decreased insulin resistance, reduced testosterone, less unwanted hair growth, clearer skin, enhanced chances of ovulation, higher egg quality, lower chance of gestational diabetes (GD), healthier liver, anorexia and food cravings, more stable mood, help for symptoms of menopause, less inflammation and panic, improved nerve function, fat degradation and cost effective.

\section{Complications of PCOS can include [12-19]}

I. Fertility Problem

II. Gestational diabetes (GD) or pregnancy-induced high blood pressure

III. Miscarriage or premature birth

IV. Nonalcoholic steatohepatitis

V. Metabolic syndrome like High B.P

VI. Type-II diabetes or prediabetes

VII. Sleep apnea

\section{Depression, worsen anxiety and eating disorders}

IX. Abnormal uterine bleeding

X. Cancer of the uterine lining (endometrial cancer)

\section{Conclusion}

SLS continues to be a major global health problem that represents the challenges to our health care systems. It shows a too much need for more public education and health awareness on SLS in the country. In comparison with other complications remains one of the least understood and the most confusing medical conditions by health care public and also for the other population and least funded endocrine disorder. Even World Health Organization (WHO), ACOG (American Congress of Obstetricians and Gynecologists) and National Institutes of Health (NIH) also mentioned in its report that in most of the countries where; SLS is a major public health concern. According to the scale of the public health problem, there must be a comprehensive approach to prevention and management of SLS is urgently required for the major fertility problem in women's. There are various programs like surveillance and education must be delivered at the community and rural level through the primary health care (PHC) system so as to increase public awareness about the problem and lengthen the survival of affected individuals and also, prevent the general from becoming affected. The most important challenge is thus to improve the projection for implementation of research for the patients with SLS in developing countries. This study may benefit government to find a new vision and mission in control of SLS. So, our aim to investigate the understanding and to study the changes of the hormonal profile in SLS adolescents. Also, the lifestyle management program on clinical symptoms of the adolescent SLS.

\section{References}

1. Lujan ME, Jarrett BY, Brooks ED (2013) Updated ultrasound criteria for polycystic ovary syndrome: reliable thresholds for elevated follicle population and ovarian volume. Hum Reprod 28(5): 1361-1368.

2. Stepto NK, Cassar S, Joham AE, Hutchison SK, Harrison CL, et al. (2013) Women with polycystic ovary syndrome have intrinsic insulin resistance on euglycaemic-hyperinsulaemic clamp. Hum Reprod 28(3): 777-784.

3. Yildiz BO, Bozdag G, Yapici Z, Esinler I, Yarali H (2012) Prevalence, phenotype and cardiometabolic risk of polycystic ovary syndrome under different diagnostic criteria. Hum Reprod 27(10): 3067-3073.

4. Goodarzi MO, Dumesic DA, Chazenbalk G, Azziz R (2011) Polycystic ovary syndrome: etiology, pathogenesis and diagnosis. Nat Rev Endocrinol 7(4): 219-231.

5. March WA, Moore VM, Willson KJ, Phillips DI, Norman RJ, et al. (2010) The prevalence of polycystic ovary syndrome in a community sample assessed under contrasting diagnostic criteria. Hum Reprod 25(2): 544-551.

6. Nicandri KF, Hoeger K (2012) Diagnosis and treatment of polycystic ovarian syndrome in adolescents. Curr Opin Endocrinol Diabetes Obes 19(6): 497-504. 
7. Wang ET, Cirillo PM, Vittinghoff E, Bibbins-Domingo K, Cohn BA, et al. (2011) Menstrual irregularity and cardiovascular mortality. J Clin Endocrinol Metab 96(1): E114-E118.

8. Dokras A, Clifton S, Futterweit W, Wild R (2011) Increased risk for abnormal depression scores in women with polycystic ovary syndrome: a systematic review and meta-analysis. Obstet Gynecol 117(1): 145-152.

9. Teede H, Deeks A, Moran L (2010) Polycystic ovary syndrome: a complex condition with psychological, reproductive and metabolic manifestations that impacts on health across the lifespan. BMC Med 8: 41 .

10. Boyle JA, Cunningham J, O’Dea K, Dunbar T, Norman RJ (2012) Prevalence of polycystic ovary syndrome in a sample of Indigenous women in Darwin, Australia. Med J Aust 196(1): 62-66.

11. Teede HJ, Misso ML, Deeks AA, Moran LJ, Stuckey BG, et al. (2011) Assessment and management of polycystic ovary syndrome summary of an evidence-based guideline. Med J Aust 195(6): S65-S112.

12. Moran L, Gibson-Helm M, Teede H, Deeks A (2010) Polycystic ovary syndrome: a biopsychosocial understanding in young women to improve knowledge and treatment options. J Psychosom Obstet Gynaecol 31(1): 24-31.
13. Unluhizarci K, Kaltsas G, Kelestimur F (2012) Non polycystic ovary syndrome-related endocrine disorders associated with hirsutism. Eur J Clin Invest 42(1): 86-94.

14. Misso ML, Wong JL, Teede HJ, Hart R, Rombauts L, et al. (2012) Aromatase inhibitors for SLS: a systematic review and meta-analysis. Hum Reprod Update 18(3): 301-312.

15. Bargiota A, Diamanti-Kandarakis E (2012) The effects of old, new, and emerging medicines on metabolic aberrations in PCOS. Ther Adv Endocrinol Metab 3(1): 27-47.

16. Norman RJ, Masters SC, Hague W, Beng C, Pannall P, et al. (1995) Metabolic approaches to the subclassification of polycystic ovary syndrome. Fertil Steril 63(2): 329-335.

17. Carmina E, Koyama T, Chang L, Stanczyk FZ, Lobo RA (1992) Does ethnicity influence the prevalence of adrenal hyperandrogenism and insulin resistance in polycystic ovary syndrome? Am J Obstet Gynecol 167(6): 1807-1812.

18. Roberts DW, Haines M (1960) Is there a Stein-Leventhal syndrome? Br Med J 1(5187): 1709-1711.

19. Givens JR (1984) Polycystic ovaries-a sign, not a diagnosis. Sem Reprod Endocrinol 2: 271-280

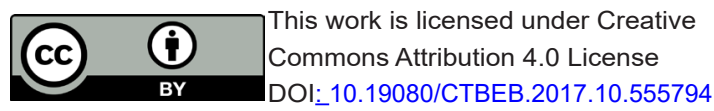

Your next submission with Juniper Publishers will reach you the below assets

- Quality Editorial service

- Swift Peer Review

- Reprints availability

- E-prints Service

- Manuscript Podcast for convenient understanding

- Global attainment for your research

- Manuscript accessibility in different formats ( Pdf, E-pub, Full Text, Audio)

- Unceasing customer service

Track the below URL for one-step submission https://juniperpublishers.com/online-submission.php 